\title{
Género y poder en la ficción televisiva: análisis textual ideológico de una serie histórica
}

\section{Gender and power in television fiction: an ideological textual analysis of a historical TV Series}

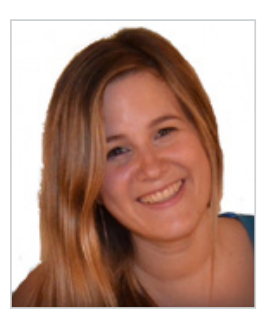

Mayte Donstrup. Personal Investigador en Formación (VI Plan Propio US) en el Departamento de Comunicación Audiovisual y Publicidad de la Universidad de Sevilla. Miembro del grupo de investigación IDECO (Comunicación Política, Ideología y Propaganda). Actualmente se encuentra en el proceso de realización de su tesis doctoral centrada en el estudio de recepción ideológica de las series de ficción de contenido político. Sus líneas de investigación se centran en el análisis ideológico de los discursos mediáticos y la propaganda. Asimismo, dentro de estas áreas, ha participado en diversos congresos internacionales y publicado en revistas nacionales e internacionales.

Universidad de Sevilla, España

mdonstrup@us.es

ORCID:0000-0001-6236-4967

Recibido: 17/01/2019 - Aceptado: 29/04/2019

\section{Resumen:}

Las producciones enmarcadas dentro de la tercera edad dorada televisiva gozan de una amplia fama en la actualidad. Dentro de las series situadas en esta categoría se pueden hallar, ocasionalmente, mujeres que ejercen puestos de poder, tal como se da en la serie a examinar en este artículo: Vikings, donde una de las principales protagonistas, Lagertha, acapara gran admiración por parte de la audiencia femenina. Este caso se examinará con el objetivo de saber si ese éxito se corresponde con la realidad del personaje (su personalidad y las acciones que ejecuta), realizando para ello un análisis que determinará el arquetipo de la protagonista y desarrollando un análisis semiótico del personaje y sus relaciones de poder con los demás sujetos.

\section{Palabras clave:}

Poder; series; género; televisión; ficción.
Received: 17/01/2019 - Accepted: 29/04/2019

\section{Abstract:}

Productions carried out during the third golden age of television enjoy widespread popularity today. Within some of the TV series in this category, women who hold positions of power can occasionally be found as in the TV show analyzed in this article, which is Vikings. In this series, one of the main protagonists, Lagertha, amasses great admiration from the female audience. In order to know if this success corresponds to the reality of the character (her personality and the actions she takes), this study will carry out an analysis to determine the archetype of the protagonist and to develop a semiotic study of the character and her power relations with other subjects.

\section{Keywords:}

Power; TV series; gender; television; fiction.

\section{Introducción}

Las series de televisión se han convertido en un objeto de análisis priorizado en el seno de las investigaciones en comunicación; en parte, como consecuencia de la llamada "burbuja televisiva" y la amplia gama disponible de series de calidad en la actualidad. Un desarrollo académico que, por otra parte, no se puede entender sin los antecedentes anteriores: tales como la obra Apocalípticos e integrados, donde Eco realizó una defensa del análisis de la televisión como objeto cultural;

Cómo citar este artículo:

Donstrup, M. (2019). Género y poder en la ficción televisiva: análisis textual ideológico de una serie histórica. Doxa Comunicación, 28, pp. 97-109. 
un medio con sus propias características y merecedor de la atención de los investigadores (2009: 330). De esta forma progresivamente empezó a germinar un interés por la investigación del medio televisivo; así, Williams (1990) abogó por estudiar la televisión a partir de los usos y posibilidades que este medio pudiera tener, alejándose entonces de las posturas deterministas del momento. Un creciente interés por la contemplación de la audiencia al que siguió Morley (1996) apostando por el análisis de la recepción a partir de propuestas etnográficas con el fin de entender adecuadamente los sentidos que les otorgaban los espectadores a los textos televisivos. Por su parte, en el espacio específico de las series de televisión pionero es el trabajo Interacting with Dallas: cross cultural readings of american TV (Katz y Liebes, 1990) donde se analizaba cómo los espectadores de diferentes países descodificaban diferentemente la misma serie.

Porque, al igual que se tornaba interesante estudiar los textos televisivos, pronto el terreno académico se mostró interesado por saber cómo estos eran interpretados. Bajo este prisma, Vikings (History Channel, 2013- ) se antoja como una serie que proporciona una interesante lectura referida a la representación del género y el poder; en este sentido, tiene como una de sus principales protagonistas a una intrépida guerrera que, a priori, resulta ser una gobernante excepcional. Un efectivo gobierno que es afirmado en entrevistas por el creador de la serie Michael Hirst (History Extra, 2017) o en la misma página oficial de la producción: "respected warrior and the Queen of Kattegat [...] fiercely independent" (Vikings Cast, s/a). El personaje en cuestión es Lagertha, una mujer que aparentemente también es admirada por la audiencia femenina. Así, tal como muestran las imágenes aportadas como ejemplo, buscando su nombre en una navegación superficial por la red, se encuentran diversas fotografías del personaje donde destacan su valentía.

Por tanto, se puede ver que las series de televisión pueden servir como vehículos de modelos a seguir por las jóvenes, y, en ocasiones, esos modelos no son tan transgresores como aparentan ser. Con esta base, este artículo tiene como objetivo discutir la representación de la mujer con poder en la serie canadiense Vikings a partir del análisis de su protagonista femenina principal. Un objetivo que se alcanzará por medio de dos vías: en primer lugar, con un análisis del personaje en cuestión. En segundo orden, una comprobación de la percepción de Lagertha en la plataforma Twitter, donde se recopilarán los comentarios que vierten sobre ella los usuarios de esta red social. De este modo, se comprobará si la imagen intencionada de la serie corresponde con el papel representado y con la idea que el público tiene de ella.

Ilustración 1: Lagertha en redes sociales
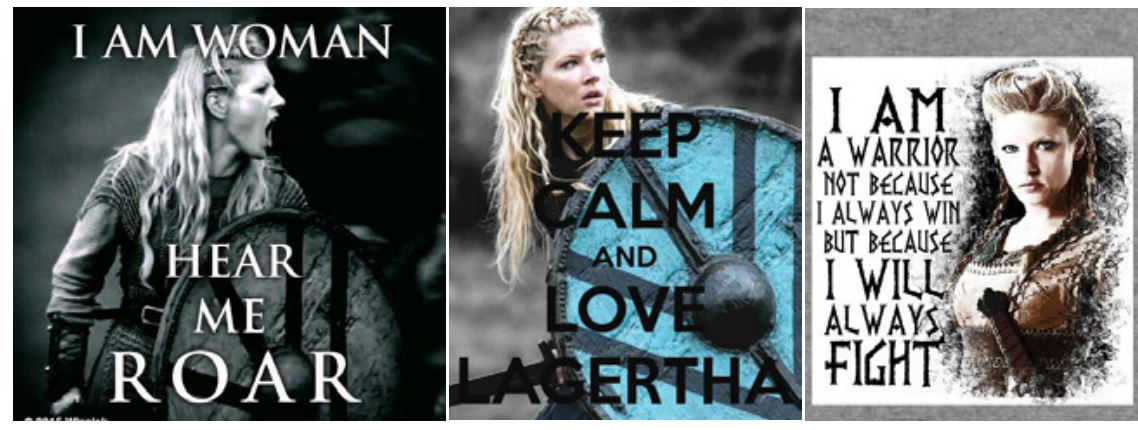

Fuente: Tumblr 


\section{Método}

Esta investigación parte de la observación del grado de admiración que algunos personajes femeninos acaparan en la actualidad, siendo percibidos, en algunos casos, como modelos a seguir debido a su fuerza y valentía. Este es el caso concreto de Lagertha, protagonista de la producción canadiense Vikings, un personaje que en la primera impresión sí parece haber roto el 'techo de cristal', pues expresa su opinión sin reparos, acude a batallar junto a los hombres y se separa de su marido cuando este la engaña, pero ¿ison estos rasgos suficientes para romper los roles tradicionales asociados al género?

Con el objeto de responder a esta cuestión y detectar la fidelidad, o no, de este personaje a los principios que $a$ priori se le adjudican (History Extra, 2017; Vikings Cast, s/a) se va a realizar un análisis textual, siguiendo las premisas expuestas por Hermida Bellot (2013), que permita descubrir el arquetipo que se encuentra detrás del personaje. Es decir, se visionarán las tres primeras temporadas de la serie -con un total de 29 capítulos- con apuntes de las principales acciones del personaje que permitan dilucidar su personalidad para asociarla, además, con alguno de los arquetipos propuestos por Lynn Schmidt $(2001,2012)$. Por otra parte, este análisis se completará con un análisis ideológico atendiendo a la definición de van Dijk (2000) de ideología: esquemas que sirven para la representación de grupos sociales a través de la delimitación de Nosotros vs Ellos. A su vez, esta parte será respaldada por teóricos del poder (Russell, 2017; Galbraith, 2013; Greene, 2003; Maquiavelo, 1983), con el objeto de estudiar las acciones que ejerce la protagonista y así establecer su éxito o su fracaso.

Por último, para responder a la cuestión de la percepción de la posición de poder de Lagertha por parte de los seguidores de la serie, se ha diseñado una búsqueda de opiniones en Twitter sobre el personaje. En esta línea, se ha realizado una búsqueda manual con Twitter Search con las palabras clave Lagertha y Líder con el objetivo de acotar el universo al fin específico: recopilar las opiniones de los usuarios/as cuando reflexionan sobre el personaje como gobernante. El contenido de las publicaciones del corpus se analizó a partir de una plantilla que permitió codificar cualitativamente los datos extraídos de la red social. Cada tweet referido a Lagertha como líder fue considerado como una unidad de análisis a partir de la cual se codificaron los enlaces que ofrecían -imágenes o vídeos- así como las menciones que realizaban sobre ella.

Tabla 1: Ficha de análisis

\begin{tabular}{|c|c|c|c|c|c|}
\hline Tweet & Imagen & Texto & Positivo & Negativo & Neutro \\
\hline & & & & & \\
\hline
\end{tabular}

Fuente: elaboración propia

La ficha de análisis se ha dividido en cinco secciones: en primer lugar, se ha detectado la presencia o la ausencia de imagen con el objeto de percibir la representación que hacen de ella -como guerrera, como madre o en otra situación-. En segundo orden, se ha transcrito e interpretado en su conjunto todo el contenido del tweet con el objeto de interpretar su contenido. Por último, se ha cotejado el tweet en general: calificación positiva, negativa o neutra -no descalifican al personaje, pero tampoco lo alaban-.

En definitiva, los hallazgos se dividen en tres partes: la primera relacionada con la dimensión arquetípica del personaje; la segunda con la intersección entre las teorías del poder y las acciones de Lagertha; por último, los resultados de los comen- 
tarios vertidos en la red. Todo ello permitirá alcanzar el objetivo principal de este trabajo: comprobar si el personaje de Lagertha corresponde con la percepción que tiene de ella el público, siendo las dos primeras secciones las que permitan conocer al personaje y la última la que dé acceso a la opinión de los seguidores.

\section{Lagertha: el arquetipo de una vikinga en la tercera edad dorada televisiva}

Vikings narra la leyenda de Ragnar Lodbrok, quien representa el mito del hombre hecho a sí mismo: un intrépido guerrero que subirá paulatinamente en la escala social gracias a sus habilidades como estratega. Por el contrario, Lagertha-su mujer y objeto de análisis de este trabajo- es presentada en las primeras escenas como una madre que atiende las tareas del hogar. En efecto, Lagertha asumirá a lo largo de la serie, principalmente, el papel de amante de Ragnar, al que profesa un amor incondicional; y si en diversas ocasiones demuestra que ella también posee dotes de guerrera, esta faceta parece que fue olvidada por su círculo más cercano al asumir el matrimonio y la maternidad. Un hecho que se ve, por ejemplo, cuando el hermano de Ragnar hace referencia a sus dotes de escudera como una ocupación pasada (1x01, "Rites of Passage").

A su vez, si el personaje demuestra en ciertas ocasiones señales de independencia, sus decisiones serán tomadas según lo considere su marido puesto que su sed de aventura no será calmada hasta el permiso de este (1x03. "Dispossessed"); Episodio en el cual se la verá por primera vez vestida de escudera al permitirle Ragnar que acuda a las incursiones a Inglaterra. Ahora bien, la máxima prioridad que manifestará Lagertha será complacer a su marido, y él, para sentirse completo, necesitará tener descendencia. En este sentido, Ragnar -quien ya será conde en estos episodios-no se considerará dichoso puesto que Lagertha ha tenido un embarazo fallido; y, por ello, se mostrará reacio ante ella. Dicho esto, tras unos capítulos de agonía por la situación, ella se refugiará en sus creencias religiosas y pedirá a sus dioses que le den un hijo. Plegarias que son escuchadas: Ragnar volverá a ser padre, pero con otra mujer: Aslaug, una völva capaz de predecir el futuro.

En la segunda temporada, Lagertha se enterará por su hijo, Bjorn, del desliz que tuvo su padre con Aslaug, infidelidad que acabará perdonando tras un breve enfado. Sin embargo, la amante aparece en la aldea embarazada, y, tras una conmoción inicial, en un gesto que parecerá ser de amor propio, abandona a Ragnar y se marcha con su hijo de Kattegat (2x01, "Brother's War"). Aunque en un reencuentro posterior Lagertha saludará afectivamente a los hijos de Aslaug y Ragnar, comentándoles a los niños, orgullosa, que siempre supo que conocería a más hijos de Ragnar, pues los dioses se lo dijeron (2x05, "Answers in Blood"). Es por ello por lo que demuestra que su abandono fue una prueba de amor hacia Ragnar, para que otra mujer le pudiera dar los hijos que ella no podía darle. A su vez, esta temporada incorpora un salto temporal de cuatro años, transcurso en el que Lagertha subirá en la escala social gracias a otro matrimonio con un duque.

En esta tanda de capítulos, Bjorn se enterará del asalto de las tierras de su padre y Lagertha, en una actitud sugerente, intentará conseguir el apoyo de su nuevo marido para salir en ayuda de Ragnar con sus hombres. Una proposición que será rechazada por lo que, ante la negativa de este -visiblemente celoso-, acudirá sin su permiso para socorrerle. Acción que le valdrá una paliza a su vuelta por parte de los hombres de su esposo, quien posteriormente intentará humillarla en un acto público. Un evento donde acabará masacrado por ella, que, en consecuencia, conseguirá el cargo de condesa. Empero, más adelante se descubrirá que Lagertha consiguió apoyos adicionales para llevar a cabo el plan: Einar, miembro de una familia poderosa de su nuevo condado que reclamará disfrutar de su cuerpo a cambio de ayudarla. No obstante, 
Lagertha negará posteriormente la promesa y, tras un coqueteo con el mismo, le rechazará como amante (2x08, "Boneless”). Tras esta acción, ella decidirá retornar con Ragnar y saquear Inglaterra junto a él para ayudarle a calmar su sed de venganza contra el rey inglés. No obstante, la maniobra de Lagertha de abandonar su recién adquirido condado tendrá consecuencias colaterales.

En la tercera temporada, Lagertha es despojada del poder por el hombre en el que más confiaba, Kalf, su mano derecha. En ese momento, pedirá ayuda a Ragnar y, al igual que ella le ayudó en su momento, le pedirá volver juntos y echar al usurpador de sus tierras. En contra, él no considera que ese hecho sea relevante e irá junto a ella al condado, pero para pedirle a Kalf que se una a ellos en una nueva expedición hacía París. Una traición por la que ella se sentirá visiblemente molesta; no obstante, reaparecerá para ir con ellos hacia nuevas tierras: Francia. Unas primeras incursiones que resultarán ser un desastre para los vikingos y en la que ella será salvada por Kalf, con quien se casará posteriormente.

¿Qué expresan todos estos datos sobre el personaje? Con el objeto de expresar su rol en la serie resulta interesante observar su arquetipo, definido como "model that is imitated to the point of ubiquity and an almost subconscious recognition" (Penman y Cloud, 2018: 111). Así, tras examinar decenas de cuentos rusos, Propp detectó que su gran mayoría los personajes se desarrollaban según esquemas similares y con semejantes estructuras narrativas: las funciones. Entendidas estas como "la acción de un personaje definida desde el punto de vista de su significación en el desarrollo de la intriga" (2001: 33). Es decir, elementos constantes y permanentes que constituyen su personalidad (2001: 34). Unas funciones y recorridos de los caracteres que fueron reexaminadas posteriormente bajo el prisma del patrón narrativo mítico por Campbell, quien dijo que los arquetipos pueblan el inconsciente colectivo: "en todo el mundo habitado, en todos los tiempos y en todas las circunstancias, han florecido los mitos del hombre; han sido la inspiración viva de todo lo que haya podido surgir de las actividades del cuerpo y de la mente humana" (2013: 11).

Resulta de interés señalar que, en este sustrato colectivo de la narración, la figura femenina puede ser el héroe que supera sus limitaciones personales (2013: 26). No obstante, el destino de la heroína en este caso será "convertirse en la consorte de un ser inmortal" (2013: 112), un destino imposible de rechazar si desea encontrar la paz. Por otro lado, es corriente encontrarse en el relato a la bruja celosa, que representa a la madre mala (2013: 64) o figuras protectoras como la viejecita servicial o el hada madrina, que protegen al héroe y lo aconsejan en su misión (2013: 72). En todo caso, por lo general, la figura principal femenina ha sido la Madre Universal, y el encuentro con ella por parte del héroe en la cumbre, su recompensa por ganar: "la mujer, en el lenguaje gráfico de la mitología, representa la totalidad de lo que puede conocerse" (2013: 110).

Por los datos inferidos de la serie, en Lagertha prevalece el arquetipo de la matriarca. De este modo, con el rol de madre y esposa, su familia es lo primero, tal como demuestra en diversas ocasiones otorgando un mayor privilegio a la posición de su marido o la de su hijo. Además, de acuerdo con Lynn Schmidt, la máxima creencia de este arquetipo es: "Siempre saca tiempo para tu compañero" (2012:10). Una función que ella cumplirá, anteponiendo siempre a su marido; por ejemplo, cuando espera a Ragnar ante el ataque de la aldea poniendo en peligro su vida y la de sus hijos. Esto, por otra parte, no quiere decir que desatienda a sus vástagos, pues no cesa de cuidar a su hija hasta la muerte de esta en la primera temporada, y respecto a Bjorn, siempre estará a su lado aconsejándole y velando por él.

En contraste, el perdón de la infidelidad no lo haría la matriarca, pero un arquetipo presente en Lagertha lo posibilita: la mística. Mujer espiritual, sus dioses la guían por el camino: ella siente que los dioses le tienen un destino escrito y ella 
aceptará con confianza el sino que le tengan preparado. Esta faceta muestra a un personaje empático y comprensivo que sale a relucir en el momento en que se deja llevar por su mitología y que explica su simpatía hacia Aslaug. De esta forma, sus creencias mitológicas son las que le ayudan a superar el trauma de la separación: los dioses ya le dijeron que ella no volvería a ser madre, por tanto, su destino y el de Ragnar se encontraban separados. Sin embargo, otro arquetipo hace presencia en Lagertha, personaje sexualizado en cierta manera: la musa seductora. Este arquetipo sale a la luz en su relación con otros hombres, sobre todo hombres con poder o que le ayuden a conseguirlo, pues sabe de su atractivo y lo usará si es necesario para conseguir sus propósitos. Así, sin que lleguen a realizar el trabajo sucio por ella, sí se servirá de su físico en diversas ocasiones para lograr una posición más alta en la escala social.

Como dato de interés cabe resaltar que este personaje podría resultar engañoso, pues podría catalogarse por ciertas acciones como la amazona. No obstante, hay un hecho que elimina totalmente esta posibilidad: permitir, por órdenes de Ragnar, la matanza de las hijas pequeñas del rey Horik (2x10, “The Lord's Prayer"). Una acción que nunca hubiese sido permitida por una amazona, anteponiendo las órdenes de un hombre y permitiendo que débiles e indefensos mueran. Más bien parece ser que la producción ha dotado de ciertos rasgos superficiales de autosuficiencia a Lagertha para atrapar a un sector de audiencia femenino. En consecuencia, en Lagertha cohabitan tres arquetipos, dos de ellos con más fuerza: la matriarca y la mística, siendo la musa seductora un tercero que sale a la luz en momentos puntuales. De modo que el personaje no llega a abandonar nunca el rol que tiene asignado de madre y esposa. Por consiguiente, aun estando separada de Ragnar, este seguirá en su mente y en su corazón. Un manifiesto amor que hará que no dude en a abandonar su recién adquirido papel de gobernante para ayudarle a él en su gobierno: una acción que le valdrá la retirada del mando de sus propias tierras.

\subsection{Liderazgo y género: ¿las vikingas pueden gobernar?}

"Power is only given to those who are prepared to lower themselves to pick it up" Ragnar (3x01, "Mercenary").

Como señala Galbraith, "la historia se escribe en torno al ejercicio de poder, así como a las fuentes del mismo y los instrumentos que lo imponen" (2013: 106). En esta línea, Russell (2017) indica que, de entre las infinitas aspiraciones del hombre, las principales son los deseos de poder y gloria. Es así que el poder, junto con la gloria, continúa siendo la aspiración más alta y la recompensa más grande de la humanidad (2017: 15), por lo cual todo hombre se puede ver tentado a intentar conseguirlo. Así pues, se deduce que surge de una relación asimétrica entre personas. Además, como establece Greene: "el poder es un juego social. Para aprender a jugar y jugar bien, hay que estudiar y entender a la gente" (2007: 24). Es por ello que, al igual que es importante conocer las técnicas apropiadas para su uso, lo es también conocer a las personas sobre las cuales se ejerce, pues "ser capaz de reconocer los diferentes tipos de personas y actuar en consecuencia en fundamental" (2007: 180). En consecuencia, a continuación, se reflexionará sobre las técnicas y las implicaciones que tienen las acciones de Lagertha en la serie cuando ejerce o intenta ejercer el poder.

En un periodo histórico en el que las únicas opciones era conquistar o ser conquistado, las lecciones políticas de Maquiavelo pueden servir de utilidad para entender las relaciones de dominio y sus posibilidades de éxito. Por esta razón, se empezará realizando una lectura maquiaveliana de las tácticas de Lagertha para ejercer el poder y determinar su efectivi- 
dad, o fracaso, en las tierras convulsas que le ha tocado gobernar. Así, siguiendo a Maquiavelo (1983), un territorio puede ser conquistado gracias a dos características: la virtud o la fortuna. Mientras la fortuna, representante de lo femenino, es lo azaroso del destino; la virtud es el conjunto de las cualidades propias del sujeto que se contraponen a las fuerzas del destino. Es decir, la virtud son las propias habilidades que lo hacen un gran hombre. Unas cualidades que no tienen por qué ser honorables, puesto que lo sea o no estaría justificado por el fin que persigue. Lagertha, en este caso, asciende dos veces en la escala social gracias a sus matrimonios con dos duques: Ragnar y después Sigvard. En consecuencia, la fortuna le sonrió dos veces; sin embargo, esta puede llegar a resultar caprichosa y si su primer matrimonio debía ser motivo de orgullo (2x03, "Treachery") por el contrario su segundo marido la maltrataba. De ahí que tras acudir esta sin su permiso en ayuda de Ragnar (2x04, "Eye For an Eye") la situación derivó en unos abusos hacia ella. Por ello, decidió matarlo con la ayuda de un miembro de las familias más pudientes de su condado, Einar (2x06, “Unforgiven”). Aunque esa ayuda tenía un precio: su cuerpo, una deuda que ella rechazará pagar (2x08, "Boneless").

Por tanto, se infiere que Lagertha ha obtenido el poder a través de la fortuna, la cual le ha sonreído tres veces y le ha permitido finalmente la adquisición directa del mando. Sin embargo, si quisiera consolidar su puesto con los consejos de Maquiavelo debería considerar las siguientes cuestiones: "el conquistador que quiera asegurar sus nuevos dominios debe respetar dos cosas: la primera, que se extinga la línea de sucesión del anterior Príncipe" (1983: 10); la segunda, procurar el apoyo del pueblo y evitar que haya en el territorio una persona tan fuerte como ella. De manera que Lagertha no ha actuado acertadamente: ha dejado con deseos de venganza a Einar -sobrino del anterior duque-y, más importante aún, en una posición con la que puede actuar estratégicamente contra ella.

Dicho lo anterior, de las dos formas posibles de consecución de un territorio, Lagertha se ha hecho con él a través de la conquista, y si un terreno heredado requiere de menos esfuerzos de conservación (1983: 8), uno conquistado requiere de un tiempo de asimilación (1983: 10). A su vez, una de las reglas más primordiales de una tierra recién adquirida es residir en ellas, las cuales Lagertha opta por abandonar para intervenir en los conflictos de Ragnar (2x07, "Blood Eagle"). Por otra parte, la obtención del apoyo del pueblo, así como el evitar que en el territorio haya una persona tan fuerte como el líder, resultan ser de los actos más primordiales (1983: 12), y si bien la primera parte la obtiene, en la segunda ha dejado detrás de ella a un hombre poderoso y resentido. Por lo tanto, en consonancia con Maquiavelo, nunca es recomendable evitar una guerra, pues mientras se esté evitando el otro bando se estará haciendo más fuerte (1983: 14). De esta forma, Lagertha encargará a su hombre de confianza, Kalf, el asesinato de Einar; una acción que no hace sino empeorar su propio puesto de condesa. En este sentido, ha dejado tras de sí a dos hombres con mucho poder (3x01, "Mercenary").

Atendiendo a los consejos del florentino anteriormente expuestos, un condado recién adquirido no debería tener hombres de tal confianza en los cuales depositar semejante labor, y así como es esencial ser amado, es mucho más seguro ser temido (1983: 78). Condición no reunida por Lagertha que ha permitido que su hombre de confianza se aliara con Einar en su ausencia, arrebatándole así su condado. Así pues, la prudencia del gobernante, expuesta por Maquiavelo (1983: 112) como una cualidad básica, es una característica que no se da en Lagertha; pues si bien no era odiada por su pueblo, tampoco era querida al no pasar tiempo en sus tierras y la conspiración se materializó en poco tiempo. En concordancia con el autor, los territorios adquiridos a través de la fortuna son más fáciles de conseguir e igualmente, más difíciles de 
mantener: su territorio fue conseguido a través de la coyuntura de la familia del duque y perdido por su incapacidad de prever los peligros. En definitiva, Lagertha posee fortuna y carece de virtud.

Hay que mencionar además una característica fundamental del poder, que es ser reconocido por los demás como tal (Galbraith, 2013). En este caso, cuando Lagertha propone su ayuda como aliado a Ragnar tiene que ser a través de un pseudónimo, Ingstad, para que este acepte una reunión. A pesar de que este necesita de alianzas para derrotar a su enemigo, ella necesitará ocultar su identidad bajo la simulación de pertenecer al sexo masculino, pues como le dice después, sabía que no hubiese aceptado ni hablar con ella de la otra manera (2x07, "Blood Eagle"). Así, de acuerdo con Valcárcel (1998), más que las propias habilidades para ejercer el poder se exigen perfiles no oficiales que son incluso más valorados que las destrezas. De esta manera, sabiendo que las cualidades como guerrera de Lagertha son apreciadas se intuye que Ragnar valorará más que sea un cómplice de su mismo sexo. Por lo mismo, el tono burlesco que adquiere Ragnar cuando se dirige hacia ella como "condesa" y el consentimiento por parte de ella de esa actitud, reflejan el poco respeto que se tiene hacia su cargo.

Es por esto que Lagertha hace uso de un poder inexplícito en su mayoría, es decir, basado en la influencia indirecta; y cuando hace uso de uno explícito lo ejercerá sin la completa investidura, pues sus decisiones deberán ser ratificadas por otra persona (1998: 116). Por ilustrar con un ejemplo, cuando el rey aliado Horik se impacientó ante ella por no tener los barcos listos, sería necesaria la intervención de Bjorn para delimitar el tiempo establecido por ella (2x08, "Boneless"). Una falta de respeto hacia su cargo que se traducirá en la falta de interés de ayudarla después a la recuperación de sus tierras usurpadas; pues ante la petición de ayuda, Ragnar le reclamará si son tan valiosas sus tierras para ella (3x05, “The Usurper"). De ese modo, se entiende que no es tan capital quitarle un puesto de poder a una mujer como quitárselo a un hombre -hay que recordar que cuando le arrebataron las tierras a Ragnar él entró en cólera y ella acudió en su ayudaAsí, hasta su propio hijo le insinúa que está actuando exageradamente, tras lo cual, si bien hizo en amago de irse, se quedó al lado de Ragnar y con el propio usurpador que se unió a ellos en las expediciones (3x06, "Born Again"). En suma, si de acuerdo con Galbraith (2013) una persona con verdadero poder es la que es capaz de obtener aceptación de opiniones suyas propias, Lagertha, que tiene que acoplarse a las creencias de los demás, es una persona con limitado poder.

Respecto a sus dotes como escudera, Ehrenreich (2000) expone que son los rasgos masculinos los que se encuentran asociados a la guerra; y si bien en diversas culturas antiguas, como la mesopotámica, los dioses que representaban al derramamiento de sangre y la depredación eran del género femenino, ya en la época clásica hasta nuestros días: "la asociación de la masculinidad con la violencia y de la feminidad con la no violencia han llegado a convertirse en dogma" (2000: 155). La Era vikinga narrada en esta serie se basa en la igualdad de admisión a los campos de batalla siendo las únicas cualidades requeridas, independientemente del sexo, destreza y fuerza. En este sentido, Lagertha, y después Porunn, son las principales guerreras que ocupan los planos de las batallas. Si bien en una de ellas Porunn resultó gravemente herida, hecho tras el cual le quedó una cicatriz en el rostro que la dejó muy acomplejada y que hizo que decidiera exiliarse dejando a su hija y a su marido detrás (3x08, "To the Gates"). Este caso se puede ejemplificar con el caso de Afrodita y el cómo las diosas fieras se empezaron a representar como diosas bellas y seductoras (Ehrenreich, 2000). En la serie, mientras que los hombres que han resultado heridos durante las batallas muestran sus cicatrices sin vergüenza; en el caso de una mujer esa pérdida de belleza ha provocado un exilio. Parece ser que, al igual que los cánones modernos, además de las dotes de guerrera se observa el atractivo de ellas. 
En síntesis, Lagertha, aunque en ocasiones disponga del título de gobernanta no será considerada como tal; y si dispondrá de capacidades de actuación en el campo de lucha, tan valoradas en su poblado, estas dotes no contarán con un valor estratégico, que estará reservado a Ragnar y a su hijo.

\subsection{Discusión histórica}

¿Es fiel la imagen representada de las vikingas en esta serie de ficción? Respecto a este punto, la historiadora San José Beltrán especifica que la historia de Lagertha proviene de una saga, las cuales fueron escritas una vez finalizada la Era vikinga y que al igual que aparecían las escuderas lo hacían elementos mágicos como dragones (2014: 150). Es por ello que el personaje si bien es cierto que pudo existir, se nutre más de elementos mitológicos que reales. Por otra parte, Beltrán aclara que las mujeres guerreras forman parte del mito pues estas no participaban en los saqueos, así como tampoco gobernaban en general (2014: 153); y aunque sabían usar armas, su cometido en la sociedad era de llevar los asuntos de la casa y de transmitir la cultura popular a los hijos (2014: 155).

No obstante, no es una concepción sobre el papel de la mujer en la sociedad como se concebía en el resto de Europa pues estas disponían de total libertad si querían el divorcio, así como podían participar en los debates públicos (a través de la voz de su marido). Asimismo, el respeto hacia la mujer era un valor muy tenido en cuenta en los poblados vikingos y la violación era, por ejemplo, uno de los pocos castigos que se penaban con la muerte (2014: 155). Por consiguiente, la serie ha tomado elementos del mito y ha occidentalizado su papel, otorgándole el rol de amante y dotándola de ciertos rasgos de guerrera que hagan parecer que los roles de género han quedado suspendidos. Sin embargo, estos siguen vigentes en esta producción y mantienen el peso del personaje en aspectos relacionados con el amor. Una importancia del aspecto romántico que suele constituir el núcleo fuerte de los personajes femeninos en la cultura de masas (Bernárdez Rodal, 2015). De modo que en Vikings este soporte se sigue cumpliendo; así, el peso de la trama de Lagertha caerá principalmente en ser la mujer de Ragnar Lodbrok. En este caso, el aparente liderazgo que se le ha otorgado a la misma ha quedado en entredicho pues a través de la interpretación del texto se ha demostrado que carece de la virtud necesaria para el cargo.

\subsection{Lagertha, ¿My Queen?}

Según Machor y Goldstein (2001) la tradición de los estudios de recepción radica en la comprensión de cómo las audiencias dan lectura y reconstruyen las narrativas provenientes de los distintos formatos culturales: obras literarias, cine, televisión... Por su parte, en España son varios los proyectos que se han interesado en estudiar las audiencias bajo este foco. En este sentido, por poner un par de ejemplos, se ha arrojado luz sobre la construcción de la identidad de menores a través de contenidos ficcionales (Pindado, 2006; Menéndez Menéndez, Figueras-Maz y Núñez Angulo, 2017) o en la construcción de identidades culturales (Repoll; 2004; Huertas, Reguero y Sagarzazu, 2010). Ahora bien, el examinar personajes que pueden servir como modelos para los seguidores también resulta de interés y con esta intención en mente se han recopilado los tweets que contenían las palabras clave Lagertha y líder. Un filtro que ha permitido recopilar un total de treinta y nueve mensajes ${ }^{1}$ :

1 Comprenden un periodo de cinco años (2013-2018) correspondientes desde la emisión de la primera temporada en España hasta la cuarta. 
Género y poder en la ficción televisiva: análisis textual ideológico de una serie histórica

Tabla 2: Resultados

\begin{tabular}{|c|c|c|c|c|c|}
\hline Tweet & Imagen & Texto & Positivo & Negativo & Neutro \\
\hline 39 & 7 & 39 & 34 & 0 & 5 \\
\hline
\end{tabular}

Fuente: elaboración propia

En un estudio sobre la competencia mediática de los españoles en relación con los medios de comunicación de masas tradicionales, Lazo y Grandío señalaron "que hay que destacar la falta de empoderamiento en la audiencia española: de actitud crítica del proceso de recepción” (2013: 127). Es decir, la audiencia examinada captaba los mensajes de manera lineal sin filtrar críticamente si lo que emitía la televisión era adecuado: "El perfil del ciudadano en la dimensión de recepción y audiencias es el de alguien que desconoce cualquier mecanismo de defensa ante los mensajes impropios que se emiten en los medios audiovisuales" (2013: 127). En este caso en concreto, en el contexto de las redes sociales y a un micro-nivel, los datos indicados por Lazo y Grandío se respaldan. Tal es así que, ninguno de los usuarios consultados, ha examinado críticamente los rasgos de gobernante que atribuyen a Lagertha. Por ejemplo, distintas usuarias se pronunciaron respecto a ella como modelo a seguir por su fuerza y personalidad:

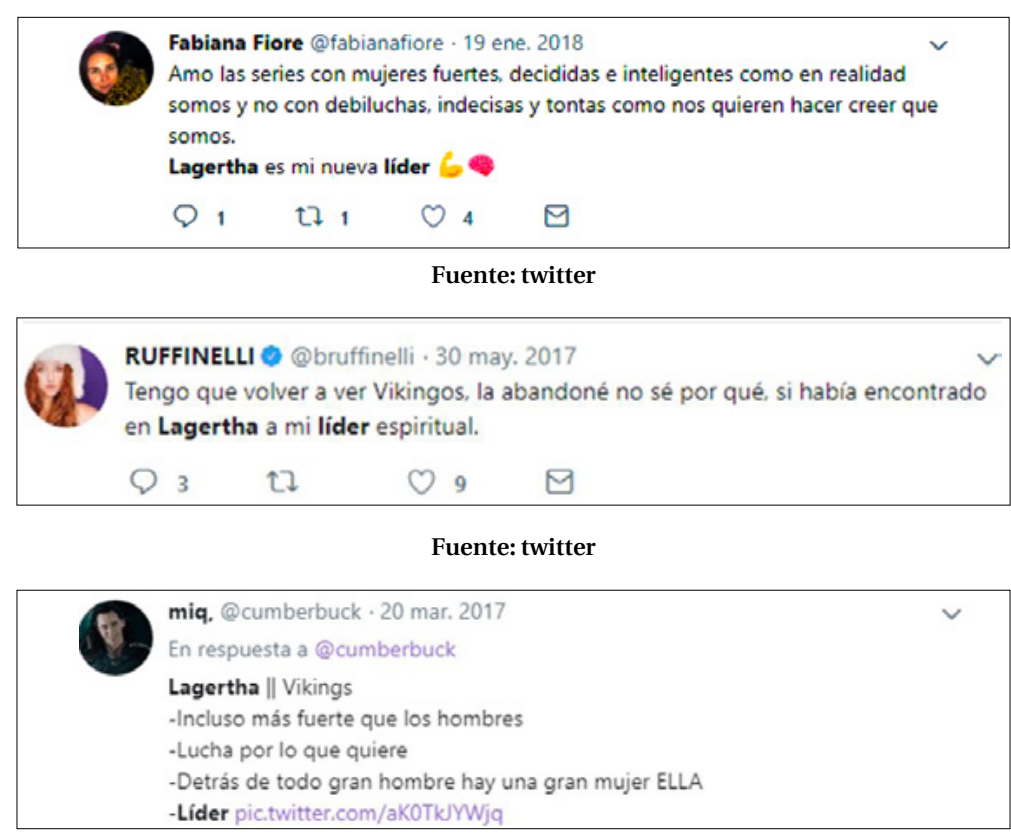

Fuente: twitter

Aparte, se debe señalar que todos los tweets positivos sobre el liderazgo de la protagonista corresponden a mujeres a excepción de cuatro hombres que la califican como la líder de la serie -uno de ellos mencionando expresamente que se 
encuentra por encima del personaje masculino, Ragnar-. En cambio, los tweets neutros corresponden a cuatro hombres, que mencionan el término líder con otro personaje masculino y a Lagertha con expresiones de afecto. En este apartado cabe destacar un tweet de una usuaria que mencionó su idea de participar en la huelga feminista del 8M con una pancarta con las protagonistas de la serie:

Rocío de Belén @taenephilim · 9 mar. 2018
\$o Mi cartel para la 8M 19' va a decir:
Se una guerrera como Lagertha
Se una lider como Aslaug
Se una mujer libre como Judith
Guarden este tweet

Fuente: twitter

En este sentido, atribuye a Lagertha las dotes de guerrera y a Aslaug, posterior esposa de Ragnar, la cualidad de líder. No obstante, el liderazgo de Aslaug queda en entredicho en varios episodios. Ella, más que nada, ejerce el papel de madre e incluso abandonó a todo su pueblo para ponerse a salvo con sus hijos cuando el poblado se encontraba bajo ataque.

\section{Conclusiones}

En el año 2007, Galán Fajardo afirmaba que, a pesar de los pequeños avances en la representación de la mujer en las pantallas, estas seguían siendo representadas bajo los mismos estereotipos "asociados, a menudo, al mundo de las emociones, la pasividad, la maternidad y la sexualidad” (2007: 45). Por el contrario, al hombre seguían correspondiendo los atributos del raciocinio, del liderazgo y la acción. Más de una década después, de aquella investigación, ¿ha cambiado la situación? ¿Qué papel interpreta la mujer líder en la ficción? Desde luego existen algunos progresos positivos, como señalan Tous-Rovirosa y Aran-Ramspott (2017) con los casos de la serie danesa Borgen (Danmarks radio, 2010-2013) y la norteamericana Madam Secretary (CBS, 2014- ); no obstante, "A pesar de un mayor protagonismo de los personajes femeninos, persiste en las series políticas una construcción de valores que adscribe los personajes femeninos a una esfera más íntima que pública" (2017: 686).

En el examen de la serie histórica Vikings, en un formato que ha entremezclado la historia con elementos mitológicos, en el personaje femenino se encuentra el arquetipo de la matriarca. Una "líder" de rasgos conservadores que no dudará en abandonar sus tareas con el fin de ayudar a su marido o de usar su cuerpo para seducir y así alcanzar sus fines. Asimismo, la matriarca en este caso no consigue obtener seguidores, por lo tanto, no se la podría considerar ni siquiera líder: su palabra será constantemente cuestionada, sobre todo por los hombres, y ella normalizará este hecho sin requerir un respeto por su supuesto cargo. De modo que once años después de la publicación de Galán Fajardo, se siguen detectando los valores de la pasividad, la maternidad y la sexualidad en los papeles femeninos.

Rasgos que destaca que sobresalgan en un personaje que, tal como arrojan los resultados, es admirado por la audiencia femenina. Un público que interpreta a Lagertha como una mujer fuerte y resolutiva. En esta línea, no es de extrañar esta 
lectura realizada por los seguidores: la producción la ha dotado con unas buenas dotes guerreras que hacen parecer que se vale por sí misma, pero ¿es eso suficiente? Que una mujer en ciertas ocasiones sepa usar armas no hace que ella se encuentre en igualdad con sus semejantes; que use su cuerpo como reclamo sexual para tener que conseguir sus fines o que siempre se cuestione a su persona sí que demuestra que se encuentra en condición de desigualdad. En definitiva, Vikings, a pesar de su aire transgresor, conserva rasgos tradicionales y representa a la mujer como no apta para gobernar. Por último, se debe agregar que por el tamaño de la muestra y la naturaleza del enfoque los datos de este estudio deben tomarse con cautela, ya que estos no permiten que las conclusiones se puedan generalizar. Sin embargo, se consideran como un punto de partida interesante para objetivos más ambiciosos en relación a la representación de personajes femeninos ejerciendo el poder y su recepción por parte de la audiencia.

\section{Referencias bibliográficas}

Bernárdez Rodal, A. (2015). Mujeres en medio(s). Propuestas para analizar la comunicación masiva con perspectiva de género. Madrid: Fundamentos.

Campbell, J. (2013). El héroe de las mil caras: psicoanálisis del mito. Madrid: Fondo de Cultura Económica.

Claire [usuario] (2018) Keep Calm and Love Lagertha [mensaje de un blog]. Recuperado de https://www.keepcalm-o-matic.co.uk/p/keep-calm-and-love-lagertha/

Eco, U. (2009): Apocalípticos e Integrados. Barcelona, Fabula Tusquets.

Ehrenreich, B. (2000). Ritos de sangre. Orígenes e historia de las pasiones de la guerra. Espasa: Madrid.

Galán Fajardo, E. (2007). “Televisión Iberoamericana: Mujer, realidad social y ficción”. Revista Latinoamericana de Comunicación Chasqui, 097, pp. 44-49. Recuperado de http://www.redalyc.org/pdf/160/16009708.pdf

Galbraith, J. K. (2013). La anatomía del poder. Barcelona: Ariel.

Hermina Bellot, C. (2013). Utilización del análisis textual en el estudio de las series de ficción televisivas: el caso de Ally McBeal. En Vicente Mariño, M., González Hortiguela, T. y Pacheco Rueda, M. (Coords.), Investigar la Comunicación hoy. Revisión de políticas científicas y aportaciones metodológicas, Universidad de Valladolid, pp. 629-644.

Huertas, A., Reguero, N. y Sagarzazu, I. (2010). Integración social y consumo mediático y cultural de los migrantes magrebíes en Cataluña. ZER - Revista de Estudios de Comunicación, 15(29), pp. 213-233.

Katz, E., y Liebes, T. (1990). “Interacting With “Dallas”: Cross Cultural Readings of American TV” Canadian Journal of Communication, 15 (1), pp. 45-66. Recuperado de: http://repository.upenn.edu/asc_papers/159

Marto Lazo, C. y Grandío, M. (2013). Análisis de la competencia audiovisual de la ciudadanía española en la dimensión de recepción y audiencia. Communication\&Society/Comunicación y Sociedad, 26(2), pp. 114-130.

Lynn Schmidt, V. (2001). Master characters. Mythic models for creating original characters. Devon: F\&W Media international. Lynn Schmidt, V. (2012). A writers guide to characterization. Archetypes heroic journeys and other elements of dynamic character development. Devon: F\&W Media international. 
Machor, J. y Goldstein, P. (2001). Reception Study: From Literary Theory to Cultural Studies. Nueva York: Routledge. Maquiavelo, N. (1983). El Príncipe. Barcelona: Planeta.

Menéndez Menéndez, M. I., Figueras-Maz, M. y Núñez Angulo, B. F. (2017). “Consumo y percepción juvenil sobre la ficción seriada televisiva: influencia por sexo y edad”. OBETS. Revista de Ciencias Sociales, 12(2): pp. 369-394. doi:10.14198/ OBETS2017.12.2.03

Morley, D. (1996). Televisión, audiencias y estudios culturales. Buenos Aires: Amorrortu.

Penman, W. y Cloud, D. (2018). "How people make sense of Trump and why it matters for racial justice". Journal of Contemporary Rhetoric, 8(12), pp. 107-136.

Pindado, J. (2006). “Los medios de comunicación y la construcción de la identidad adolescente”. ZER, Revista de Estudios de Comunicación, 11(21), pp. 11-22.

Propp, V. (2001). Morfología del cuento. Madrid: Akal.

Repoll, J. (2004). "Los otros: estudios de audiencia; una observación etnográfica de una audiencia multicultural en su interacción con la TV". ZER-Revista de Estudios de Comunicación, 9(16).

Russell, B. (2017). El poder: un nuevo análisis social. Barcelona: RBA.

San José Beltrán, L. (2014). Vikingos. Una guía histórica de la serie de History Channel. Barcelona: Quarentena.

Shieldmaiden Lagertha [usuario] (2018) I am a woman, hear my roar [mensaje de un blog]. Recuperado de https://www.tumblr.com/privacy/consent?redirect=https\%3A\%2F\%2Ftheshieldmaidenlagerthauniverse.tumblr. com\%2Fpost\%2F146176039270\%2Fi-am-woman-hear-me-roar-shieldmaiden-vikings

Thompson, R. (1997). Television's Second Golden Age. From Hill Street Blues to ER. United States of America, Syracuse University Press.

Thompson, R. (2007). "Preface” En J. McCabe y J. Akass (Eds.), Quality TV. Contemporary American Television and Beyond (pp. 17-20). London: Tauris.

Tous-Rovirosa, A. y Aran-Ramspott, S. (2017). Mujeres en las series políticas contemporáneas. ¿̇na geografía común de su presencia en la esfera pública? El profesional de la información, 26(4), pp. 684-694. https://doi.org/10.3145/epi.2017.jul.12

Valcárcel, A. (1998). La política de las mujeres. Madrid: Cátedra.

Van Dijk, T. A. (2000). Ideología. Una aproximación multidisciplinaria. Barcelona: Gedisa.

Williams, R. (1990). Television, technology and cultural form. London: Routledge. 
